\title{
DESIGNING OF DIVING TECHNOLOGIES - PROCESS APPROACH
}

\section{Ryszard Kłos}

Polish Naval Academy, Department of Underwater Work Technology in Gdynia, Poland

\section{ABSTRACT}

This article is a brief description of a new methodology ${ }^{1}$ for utilising the $N x-S C R C R A B E$ SCUBA rebreather ${ }^{2}$. This new approach differs from that described in a previous article $[1,2]$. The new methodology is based on a Polish theory ${ }^{3}$ mainly consisting of deterministic methods ${ }^{4}$ of modelling semi-closed circuit rebreathers $S C R$. Further research ${ }^{5}$ can henceforth be carried out in a more reliable and efficient manner than ever before.

Keywords: Semi-Closed Circuit Rebreather, modelling of the process of decompression.

ARTICLE INFO

PolHypRes 2019 Vol. 66 Issue 1 pp. 7 - 24

ISSN: $1734-7009$ elSSN: $2084-0535$

\section{Original article}

DOI: $10.2478 /$ phr-2019-0001

Pages: 18 , figures: 4 , tables: 0

Submission date: 07.11.2018 r.

page www of the periodical: www.phr.net.pl

Publisher

Polish Hyperbaric Medicine and Technology Society
Acceptance for print: 12.12.2018 r. 


\section{ACQUIRING KNOWLEDGE}

Descriptions of the world are becoming increasingly accurate and thus ever more complicated. Phenomena resulting from the occurring processes are most often described using models ${ }^{6}$ based on mathematical language in the form of deterministic relations ${ }^{7}$, which reflect the processes taking place in an examined system with accepted reliability.

Mathematical methods of process description are based on various foundations. If a sufficiently reliable deterministic relationship cannot be built, said descriptions are based on stochastic interpretations ${ }^{8}$, or on formulating an empirical description ${ }^{9}$. Stochastic descriptions can be naturally applied to processes with probabilistic mechanisms ${ }^{10}$. When the deterministic mechanism ${ }^{11}$ to describe the occurring processes is not known, it is the task of statistical methods ${ }^{12}$ to provide more meaning to the data ${ }^{13}$ [4].

Different types of knowledge ${ }^{14}$ are acquired in different ways, but the best way seems to be via scientific acquisition.

Science is one of the types of human knowledge distinguished by the methods and language of description used, which make up the meta-science. In the practical dimension, the task of science is to learn the truth for the purpose of later prediction, i.e. to predict the future implementation of processes taking place in defined systems.

Science ${ }^{15}$ consists of theories. A well-defined theory has a precise place in the system of knowledge, a fixed object of cognition, environment ${ }^{16}$, methods and language ${ }^{17}$. Science about the methods and language of a particular field of science is a meta-science ${ }^{18}$ referred to as methodology ${ }^{19}$ An excellent definition of theory, including model perception and the need for validation 20 was given by Pope Francis 21 - "Theory is a meta-scientific construct separate from, but consistent with, the results of observation. Thanks to theory it is possible to combine into a whole a set of independent data and facts and to explain them by means of a uniform interpretation. Theory is correct in so far as it can be verified; it is constantly evaluated against facts; once it ceases to reflect facts, it exposes its limitations and uselessness. It then calls for reconsideration" [6].

Although experimenting is difficult, expensive, time-consuming, often controversial ${ }^{22}$, ambiguous or even in given conditions impossible or unprofitable, in contrast to theoretical sciences, conducting research is the only way to gain scientific knowledge in experimental sciences.

\section{HOLISTIC APPROACH}

Traditionally, when developing diving systems in Poland, the approach based on the assessment of the risk of DCS decompression disease was applied using statistical reasoning methods. The classical approach is based on statistical reasoning from experiments performed on the basis of binominal distribution ${ }^{23}$.

The available knowledge is used to design an experimental plan for the validation of the tested system, which in this case is an ergonomic human-machine system $^{24}$. The same experimental hyperbaric exposure is then multiplied with the required reproducibility and repeatability ${ }^{25}$ collecting system responses in a dichotomous form ${ }^{26}$.

The collected results are used to determine the DCS hazard, expressed as the probability of an occurrence of DCS symptoms in the future, based on the binominal distribution. Such inference requires considerable investment in experimental diving 27 . To confirm that the DCS threat is lower than $1 \%$, it is recommended to perform a minimum of 299 experimental dives without a DCS case. If during a cycle one DCS case occurs, the study should be continued until 555 experimental dives have been completed without any more DCS cases occurring in order to confirm the risk of decompression sickness on the same level [7].

Under domestic conditions, the use of a method of inference based on binominal distribution is not feasible. For this reason, up to now, screening tests have been conducted using sequential analysis [8]. A similar approach was proposed by the Naval Medical Research Institute of the US Navy [9]. The procedure ensures that decompression schedules that generate a risk of DCS symptoms of more than $10 \%$ after a maximum of 40 experimental dives ${ }^{28}$ with a probability of approximately $90 \%$ be rejected.

In Poland, such an approach was used for the entire decompression/ventilation model, as the use of this procedure to approve each decompression schedule provided for in diving technology is also unrealistic in domestic conditions ${ }^{29}$.

\section{PROCESS APPROACH}

The distinguished ${ }^{30}$ system constitutes a reasonably minimal ${ }^{31}$ set of elements together with the synergic $^{32}$ links between them, guaranteeing the implementation of the defined processes. Process is a series of actions occurring at a given time aimed at achieving a specific goal. The conditions influencing the process constitute its internal and external context ${ }^{33}$.

A system is a series of elements organised according to strictly defined rules. A relation is any kind of dependency between two or more elements of a system. The system and relations make up the structure of the system. The set of activities distinguished in the system, arranged in causal order, taking place in a specific time, constituting a study of development of something, constitutes a process.

The concepts of system and process are fundamental in system engineering, which seeks synergically optimal solutions for technical and economic systems ${ }^{34}$, capable of undisturbed maintenance of established processes throughout the system's life cycle.

Systems engineering currently seems to be the best approach to solving scientific problems, both technical and organisational ${ }^{35}$. This is an analytical method and is therefore based on the breakdown of a problematic situation into its components. The starting point should be the basic processes that the created system must support. In the case of diving technology, these will be scenarios of diving operations. The risk analyses of such operations will form the basis for the development of a database of emergency scenarios. Analysis of the main and emergency processes of the adopted technology of diving operations allows the creation of an optimal technical and organisational 
system in which the required processes can be safely carried out.

From the very beginning of works on decompression systems for diving apparatuses in Poland ${ }^{36}$ it was decided that domestic progress is possible only through the search for deterministic models ${ }^{37}$. Consistent adherence to this assumption by three generations of researchers has led to the development of effective methodologies that do not require the funding of research as extensive and lengthy as that based on statistical modelling.

The applied research approach breaks down the methods of predicting the behaviour of the ergonomic human-rebreather system into a number of related models - Fig. 1. On the basis of the research conducted to date, it seems that said division into partial models does not generate significant errors during their synthesis into a holistic model.

The methods of modelling ventilation using differential equations have been known for centuries. These are relatively simple equations which can be solved by means of mathematical analysis. However, their usefulness until recently was questioned on the grounds that some parameters of these models could not be established with sufficient accuracy 38 .

Therefore, ventilation engineering is based on semi-empirical models derived from approximate solving of a differential equation using dimensional analysis methods. For the first time, the barriers associated with the use of deterministic approach were overcome about 20 years ago after roughly 20 years of work. This also enabled mastering of the deterministic modelling of the ventilation of a submarine, a hyperbaric chamber or a mining pit. Using these achievements in industrial and sanitary engineering could lead to a change in the approach to ventilation problems [10].

Previous research on ventilation of a semiclosed circuit diving apparatus with continuous dosing of the respiratory mix was successfully completed about 20 years ago [11]. However, this type of equipment has been withdrawn from domestic use.

The approach to modelling a diving system with the use of Nx-SCR CRABE SCUBA apparatus was changed from statistical to statistical-deterministic. The basis for decompression schedules were based on several models shown in Fig. 1:

- changes in the respiratory module $\varepsilon$ in the function of depth $H: \varepsilon=f(H)$, for specified diving parameters,

- changes in the composition of the breathing mix inhaled by the diver depending on the parameters of: depth $H$, respiratory module $\varepsilon$, design parameters for the semi-closed ventilation space of the diving apparatus, premix composition $\mathrm{x}$ and temperature,

- changes in the hazard of central oxygen toxicity depending on oxygen partial pressure $\mathrm{p}$ and exposure time $t$,

- decompression planning ${ }^{39}$ and defining of the decompression profile calculated according to the selected model as a function of hyperbaric exposure time $\mathrm{t}$ and pressure $\mathrm{H}$, taking into account the influence of interfering factors such as temperature, effect of previous exposures on decompression, increased risk of oxygen central toxicity, additional workload, descent and ascent sequence, transport to the place of descent, stress load before and after diving, etc.

Function $\varepsilon=f(H)$ of changes in respiratory module ${ }^{40} \varepsilon$ depending on depth $H$ is not crucial from the point of view of reliability ${ }^{41}$ of the determination of stable oxygen values $x_{s}$ from the ventilation model. It became important because the other models are designed with a far greater accuracy. When seeking solutions for the differential ventilation model of a diving apparatus containing a system of bags placed one in the other, this parameter began to play a key role ${ }^{42}$.

Tests on the respiratory module $\varepsilon$ are well described in the available literature in relation to atmospheric pressure, as they are an important indicator of athletes' training and form the basis of many studies on effort medicine and work standardisation. To date, the transfer of these values to hyperbaric research generated a barrier for the development of diving systems.

The results of studies on respiratory module $\varepsilon$ for specific hyperbaric situations can be found in scarce specialist publications[12,13]. Nevertheless, transferring these values still means reducing the required accuracy and precision of ventilation modelling. Determining the relation $\varepsilon=\mathrm{f}(\mathrm{H})$ of changes in respiratory module $\varepsilon$ as a function of depth $\mathrm{H}$ : for predefined conditions, was carried out by conducting experimental exposures in simulated conditions on a representative group of experimental divers ${ }^{43}$.

The ventilation model allows to establish a stable oxygen content as a function of depth: $x_{s}=f(H)$, environmental parameters and effort. After taking into account the observed fluctuations of stable oxygen content $x_{S} \mathrm{x}$, for particular depths $H$, the model contributes to decompression modelling- Fig. 1.

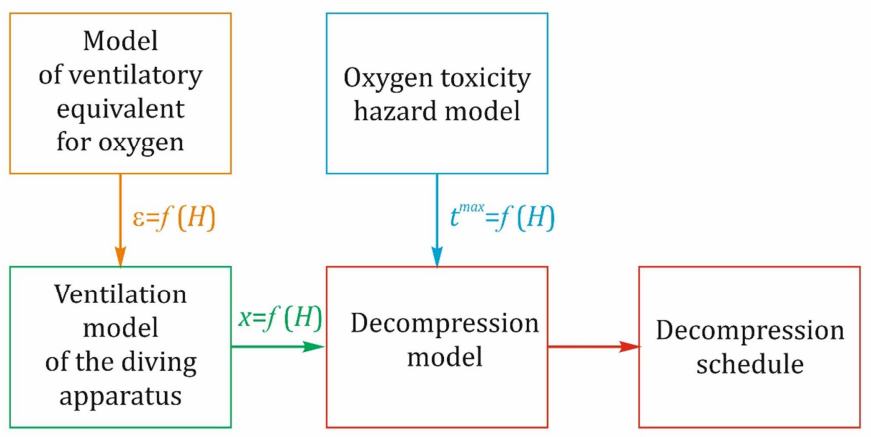


In semi-closed breathing apparatuses $S C R$ a relative decrease of oxygen content ${ }^{44}$ in the respiratory space to a stable value ${ }^{45} x_{s}$ is observed. This phenomenon is caused by the mixing of the regenerated factor with the fresh one. The dynamics of this process can be modelled similarly to other ventilation processes. Based on years of previous research, it can be concluded that the ventilation process of the SCR CRABE SCUBA breathing space can be sufficiently accurately described using the ideal gas law.

The differential equation built on the basis of the molar balance can be solved precisely. Such an approach is not commonly used because of the difficulties encountered in establishing certain parameters for this equation. Through many years of research on the process of ventilation of submarines, hyperbaric chambers, mining pits, etc., a reliable approach to this issue was proposed, hence the modelling was based on a fully deterministic, algebraic analytical model.
The process of diving apparatus ventilation without human participation was conducted at the station of accumulated simulators of: metabolic oxygen consumption $\dot{v}$, respiratory action $\dot{V}_{E}$ and depth $H$. In many respects the simulator is an original solution on a world scale which has been developed within the framework of long-term own research- Fig. 2. Its characteristic feature is that for simulating oxygen consumption $\dot{v}$ a liquid medium is used - and not gaseous as is the case in other similar technical solutions around the world [14]. As a result, it negligibly disturbs the volume of the ventilated space. The simulator set-up is characterised by an extremely short pathway between the pump simulating lung ventilation $\dot{V}_{E}$ and the tested respiratory system which does not cause compression and decompression of the breathing mix in the line inducing respiratory action, thus contributing to a more accurate modelling of real lung function.

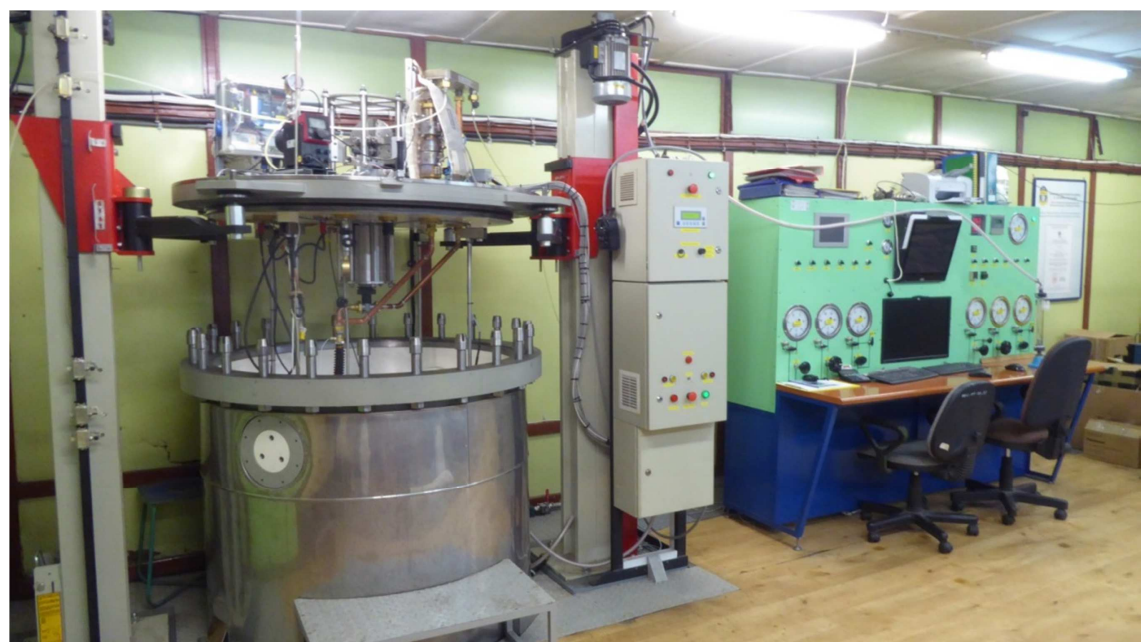

Fig. 2 Combined simulator station: respiratory, metabolic and hyperbaric.

At the same time, research was conducted in simulated hyperbaric conditions with the participation of experimental divers. The comparison of the results of these studies allowed to determine the reliability of the applied modelling of the process of ventilation and gas exchange in the ergonomic man-diving apparatus system.

Studies without experimental divers gave an answer concerning the reliability of the applied mathematical model in relation to the real object, which is the diving apparatus. Research with experimental divers identified a decrease in the reliability of the mathematical model of the diving apparatus ventilation process when disturbances related to the biometric diversity of divers are added.

Although oxygen is needed to maintain haemostasis, it also acts as a carcinogen. There are theories postulating that it is the main cause of ageing of aerobic organisms ${ }^{46}$. In hyperbaric conditions, it is more dangerous, revealing some forms of toxicity not encountered in everyday life. Under hyperbaric conditions, oxygen exhibits pulmonary ${ }^{47}$, central ${ }^{48}$ and other somatic toxicity ${ }^{49}$. In short-term military dives, the most dangerous form of oxygen toxicity is central toxicity. Experiments with CNSyn central oxygen poisoning often revealed less specific symptoms such as anxiety, facial paleness, twitching of lips and eyelids, nausea, cramps, dizziness, lack of coordination, visual and auditory hallucinations, narrowed vision or speech disorders. These symptoms rarely precede a seizure. The onset of generalised convulsions is sudden. The seizure starts with a tonic phase, usually lasting 30 seconds, during which the diver loses consciousness and the respiratory function stops. This is followed by a clonic phase with uncoordinated movements of the whole body. The whole seizure usually lasts approximately 2 minutes. If the poisoning has occurred in the water, the securing diver should try to wait until at least part of the consciousness and breathing are restored, a period of apnoea of up to 3 minutes can be allowed.

Bringing a diver to the surface without restoring respiratory action may cause pulmonary barotrauma, as oxygen poisoning and loss of respiratory action are usually accompanied by a laryngeal tightening. Severe forms of CNSyn central oxygen toxicity lead to death. There are many empirical models in the world to predict the risk of the central form of oxygen toxicity CNSyn [15].

The project was based on the widest published systematic research on modelling the threat of oxygen central toxicity CNSyn based on a mathematical survival analysis ${ }^{50}$. The model was adjusted on the basis of the 
results of research conducted by British researchers during World War II $[16,17]$ and its continuation by American scientists until the late 1970s [18]. Our own research on the adequacy of such an approach to central oxygen toxicity (CNSyn) modelling was completed with the validation of the model established by the US Navy [19].

An empirical model 52 proposed by the National Oceanic and Atmospheric Administration [20] was used to estimate the degree of relaxation ${ }^{51}$ following oxygen exposures.

The estimation of safe decompression schedules is based on the abandoned ${ }^{53} Z H-L_{12}$ model developed by Bühlmann for the Swiss army [21]. The model takes into account military conditions, such as: a specific criteria for the selection of the participating divers, keeping divers in a condition to undergo strenuous decompression, increased level of approved threat, etc. This model can be accepted as a borderline safe model. It had been validated in previously conducted studies [1,2].

As mentioned above, decompression planning has to include anticipated scenarios of expected diving operations, implemented safety measures ${ }^{54}$, rest conditions before and after diving, etc. The assessment of these parameters was carried out by experimental dives in simulated conditions, which allowed to precisely determine the permitted ranges of selected exposure parameters.

The validation of the approach was carried out, as in previous stages of the study, in a statistical way using sequential analysis [7].
As mentioned above, the deterministic models of semi-closed respiratory ventilation of the Nx-SCR CRABE SCUBA diving apparatus presented in Fig. 1, and the statistical model of central oxygen toxicity risk, were established with such reliability that the empirical model $\varepsilon=f(H)_{\theta}$ of changes in the breathing module $\varepsilon$ along with depth $H$ for a selected population of experimental divers $\theta$ as a parameter, became the element of the model with the greatest influence on the safety of the conduction of the hyperbaric exposures - fig. 3. The selected population of divers $\theta$ was a standard population admitted to military diving in the Polish Navy. Additionally, the population $\theta$ should undergo the test for deviation from the function $\varepsilon=f(H)_{\theta}$ describing changes ${ }^{55}$ in the respiratory module $\varepsilon$ with the depth $H$ as well as the oxygen tolerance text TTT [23].

A negative result of the oxygen tolerance test TTT is a premise for a diver to plan diving operations with an increased risk of central oxygen toxicity CNSyn and to be cautious when planning the treatment process using oxy-TT oxygen procedures. Deviations from the established function $\varepsilon=f(H)_{\theta}$, on the other hand, mean that for safety reasons, the diver should have a differently structured decompression. However, due to naval formalities, the negative results of these tests tend to disqualify navy divers from training with the $N x-S C R$ CRABE SCUBA.

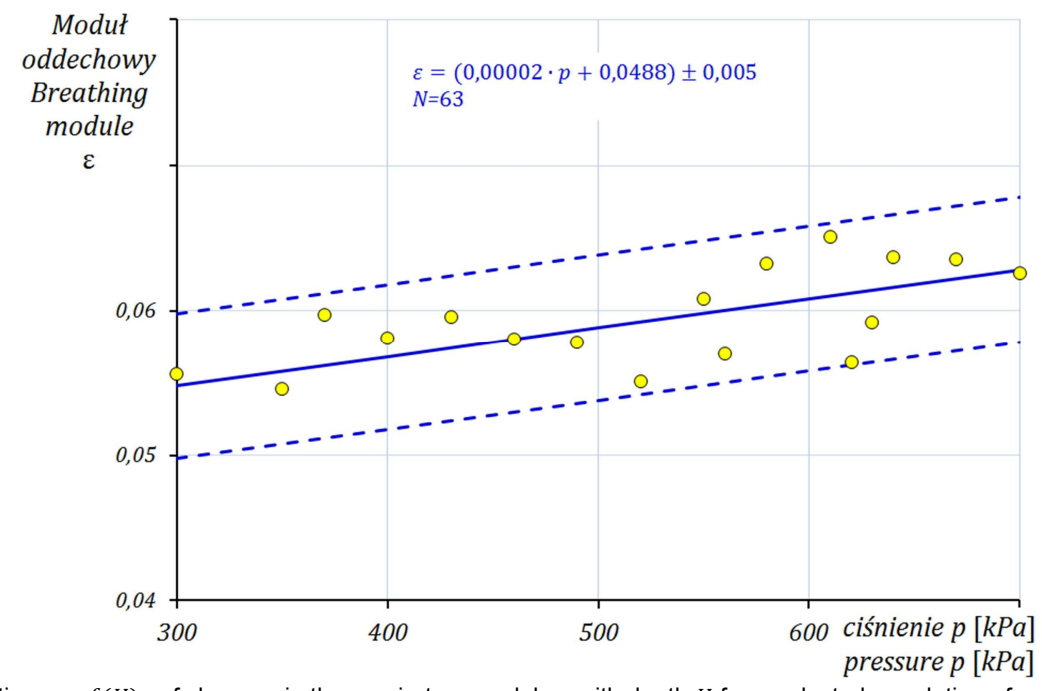

Fig. 3 The practical functional relation $\varepsilon=f(H)_{\theta}$ of changes in the respiratory module $\varepsilon$ with depth $H$ for a selected population of experimental divers $\theta$.

The potential to continuously improve the precision of decompression planning is linked to continuous improvement of the empirical model $\varepsilon=f(H)_{\theta}$ of a change in the breathing module $\varepsilon$ with depth $H$. Each dive that provides reliable ${ }^{56}$ data enhances the database allowing conclusions to be drawn about the accuracy in determining the function $\varepsilon=f(H)$ and can be used as a guideline to change the decompression schedule. Operational dives may not provide reliable data for such inference, but simulator-based training and training offer this possibility.

The inference on increasing the risk is related to the diagnosis of deviations from the empirical model $\varepsilon=f(H)_{\theta}$ of changes in breathing module $\varepsilon$ along with depth $H$. Data collected during training on the diving simulator contribute to the identification of divers for whom the decompression procedure may be potentially dangerous.

Diver testing in a diving simulator or testing of the diving apparatus on a metabolic simulator can be used to eliminate the risk of DCS. If the results of the research do not show deviations from the model $\varepsilon=f(H)_{\theta}$ and an increased risk of DCS is observed, other cuases should be sought, such as deviations from the technologies ${ }^{57}$ of performing underwater works or casuistic reasons ${ }^{58}$. Monitoring of deviations from the empirical model $\varepsilon=f(H)_{\theta}$ of changes in the breathing module $\varepsilon$ with depth $H$ provides a potential tool for an 
appointed safety officer in the Polish Navy.

\section{PROCESS APPROACH EXAMPLE}

In the execution of independent dives in the sea, for classic decompression planned with decompression stations every $3 \mathrm{mH}_{2} \mathrm{O}$, the diving set-up should incorporate an emergency decompression process with the possibility of having the last decompression station at a depth of $6 \mathrm{mH}_{2} \mathrm{O}$. Such a solution may be needed in the case of a change in wave height in the diving area or in the case of diving planned in an area with increased wave activity. In such a situation, remaining at the depth of $3 \mathrm{mH}_{2} \mathrm{O}$ is problematic for the diver. For organisational reasons, it is best to assume that the time of execution of such an emergency decompression process should be the same as for the regular decompression, and the stay at the $6 \mathrm{mH}_{2} \mathrm{O}$ station should be the sum of the time of the stay at the station at $3 \mathrm{mH}_{2} \mathrm{O}$ and $6 \mathrm{mH}_{2} \mathrm{O}$.

The risk analysis carried out at this stage shows that the decompression system should be secured with a system enabling the implementation of therapeutic recompression processes or a different medical intervention. Such a system should consist of a medical procedure and include the required technical and medical equipment. The system should be supplemented with a subsystem for evacuation of the injured diver to a specialist hyperbaric centre or hospital.

The elements of the safety system can be borrowed or developed anew to be dedicated to the system of conducting diving works. Due to the use of independent SCUBA equipment, the system of therapeutic recompression tables TT should provide for therapeutic procedures in case a diver is "ejected" from great depths with the omission of decompression stations and consequently explosive decompression takes place.

The use of semi-closed circuit SCR diving apparatus and mixtures with an increased oxygen content requires the development of a recruitment process for divers and for maintaining those divers in good physical condition. The decompression system must take into account the health parameters of divers. In this case it was assumed that they would comply with the requirements for military divers. Additional criteria ${ }^{59} \mathrm{can}$ also be added to the qualification process. The adopted standard for the physiological parameters of a diver is a guideline for the development of a procedure for the implementation of an effective decompression process.

The assumed risk of developing symptoms of decompression sickness DCS was at a higher level than for recreational divers ${ }^{60}$. The system may also include procedures for the implementation of the decompression process as for recreational divers, which will be used during training.

Due to the fact that the technology has been developed for the diving process using a semi-closed circuit rebreather SCR, it should include developed and validated effective procedures for the ventilation of the breathing space of the apparatus. The technology should assume that there will be no need to perform the process of ventilating the breathing space of the device during the stay at the bottom. However, it will always be possible to apply an effective ventilation procedure in case of suspected loss of control over the composition of the breathing mix used by the diver. These procedures increase the oxygen content in the circulation and thus their effect on the risk of an occurrence of central oxygen toxicity CNSyn should be examined.

An important parameter of a diving operation is the ability to increase the diver's workload. The value of workload is closely related to the process of ventilation of the respiratory space of the apparatus, as well as to the process of decompression and the increasing risk of central oxygen toxicity CNSyn. In this case, medium-heavy workload ${ }^{61}$ and rest ${ }^{62}$ are taken into account. In addition, it is important to bear in mind the influence of the thermal protection of the diver on the decompression process and the possibility of increasing the risk of central oxygen toxicity CNSyn.

Risk analysis has demonstrated the need for emergency breathing subsystems. Emergency breathing systems may be based on the transition from breathing from an integral cylinder to breathing from a separate redundant 63 breathing system. Such a process protects against loss of control over the essential respiratory system, but not against loss of control over the breathing mix. From the point of view of the planned process of implementation of exposures and subsequent decompression, the use of an emergency breathing system with an open circuit breathing mix must take into account an increased risk of central oxygen toxicity CNSyn. If it is considered necessary to develop procedures for the use of respiratory systems independent of the diving apparatus being used64, consideration should also be given to the phase of diving for which transition to emergency decompression is possible.

In order to secure the described main and emergency processes, a minimum ${ }^{65}$ system should consist of:

- $\quad$ procedures for qualification for diving with the intended diving apparatus and breathing mixtures,

- $\quad$ specially designed and validated procedures for basic decompression, together with rules for the permitted workload of the diver,

- specially designed and validated emergency decompression procedures,

- $\quad$ procedures for ventilating the breathing space of the diving apparatus, taking into account the increased risk of CNSyn,

- borrowed or newly developed therapeutic procedures in the event of an occurrence of diving diseases,

- hyperbaric and medical equipment to secure the treatment process,

- transport subsystem to a hyperbaric facility,

- CNSyn risk assessment procedures,

- an integral emergency respiratory subsystem of the diving apparatus,

- emergency diving apparatuses,

- thermal protection subsystem.

If, in addition, the requirement for acceleration $^{66}$ of the basic decompression process by using oxygen at the final decompression stations is introduced, the system must be further extended not only by a validated procedure for the oxygen decompression process, but also by elements resulting from the risk analysis carried out for this process.

The decompression procedure will need to define at what stage it is possible to transfer safely to oxygen decompression on the basis of the exposure 
performed and the increased partial pressure of oxygen, taking into account the resulting increased risk of central oxygen toxicity CNSyn.

Regardless of the time and depth of the transition to oxygen decompression, an effective procedure should be sought for the process of ventilating the breathing space of a diving apparatus with oxygen. The decompression acceleration algorithm will depend directly on its effectiveness. Of course, it is important to consider how to switch from oxygen decompression to a mixed gas decompression at any time ${ }^{67}$.

Preferably, the calculation of the time between decompression using a breathing mixture and oxygen should be performed following a simple rule. In most cases, a conversion rate of twice the time spent at decompression stops when breathing with the mixture than when breathing with oxygen is used. In such a case, it is sufficient to specify the stay times at the stations for the basic oxygen decompression schedule. Emergency decompression using a breathing mix will be double the time spent at the stations when breathing oxygen. The change of the breathing mix during decompression will require the development of principles for ventilating the breathing space of the rebreather. In the event of a failure of the oxygen supply from the diving apparatus, consideration may also be given to supplementing the diving operation safety system with external oxygen breathing systems ${ }^{68}$.

The use of an oxygen decompression system and emergency decompression realised when breathing with the circulating breathing mix may become complicated if the requirement is maintained as for marine systems, in relation to the use of the last decompression station at $6 \mathrm{mH}_{2} \mathrm{O}$. The imposition of such a requirement for all decompression schedules may result in the basic decompression process being too conservative and therefore ineffective from the point of view of military diving operations. In this case, it is possible to abandon this requirement for emergency decompression and to develop two decompression systems to be used depending on whether or not the dive will be protected by other oxygen sources in the event of a failure of the integral power supply.

For marine systems, a surface decompression process seems to be an attractive option. The implementation of a surface decompression process enables the interruption of the decompression process for some decompression stations, quick ascent and the access to the decompression chamber. This is followed by compression and completion of the rest of the decompression on the surface in a decompression chamber. Such a process reduces the risk connected with the diver's stay underwater, but exposes him to stress connected with the interruption of the decompression process. Interruption of decompression may last up to 7 minutes $^{69}$. It is a relatively short time for ascent, arriving at the decompression chamber, partial removal of the diving gear and repeated compression.

Surface decompression systems, as the basic procedures for the decompression process, are used for tethered dives carried out from a platform equipped with a decompression chamber ${ }^{70}$. In the case of independent dives, such procedures only serve for emergency purposes.

The system for conducting underwater works may not provide for repetitive dives, however, it should normalise the resting time that should elapse before the next dive.

\section{SUMMARY}

A scientific approach consists in an attempt to learn about the processes taking place in the examined system in such a way as to enable the forecasting of its future behaviour ${ }^{71}$ with satisfactory reliability ${ }^{72}$.

The reliable ${ }^{73}$ model deterministic model for the ergonomic human-machine system established in the project offers a sufficient reliability of prediction ${ }^{74}$. The described process of deterministic modelling by its nature enables continuous improvement of prediction precision and estimation of the hazard level, while diagnosing deviations from repeatability or model precision. Further improvements in diving technology can be carried out with effectiveness hitherto unavailable.

The Nx decompression schedules used thus far were related to the air decompression table and were based on the air table - Table 3 of the Polish Navy [24]. Recalculations were made in accordance with the principle of equivalent air depth $E A D^{75}$ [1]. Without the determination of a reliable ventilation model for a semiclosed breathing space of the Nx-SCR CRABE SCUBA rebreather, it was not possible to establish an accurate schedule for safe decompression. The currently introduced decompression tables are based on a reliable ventilation model, although it is marginalised for short periods of stay ${ }^{76}$. Fig.4. is a juxtaposition of profiles used by the French Navy FN, Polish tables based on EAD and newly developed decompression tables of the Polish Naval Academy AMW for a $40 \%$ oxygen-nitrogen mixture Nx 0.4. Field I shows that the FN profiles and the derivatives of Table 3 of the Polish Navy MW are created according to a different philosophy as compared with the tables of the Polish Naval Academy AMW.

FN profiles and derivatives of Table 3 of the Polish Navy were developed according to the traditional approach based on the generation of the maximum safe saturation of the main tissue in the initial decompression phase and subsequent counteraction of potential precipitation of a free gas phase. The profiles of the Polish Naval Academy AMW were generated on the basis of the philosophy of deep stops. They are characterised by a more effective ${ }^{77}$ decompression for longer decompression schedules from Table 3 of the Polish Navy based on EAD, and according to the newly developed procedure by the Polish Naval Academy - Nx 0.4 AMW stay times - fig. 4 area I. 


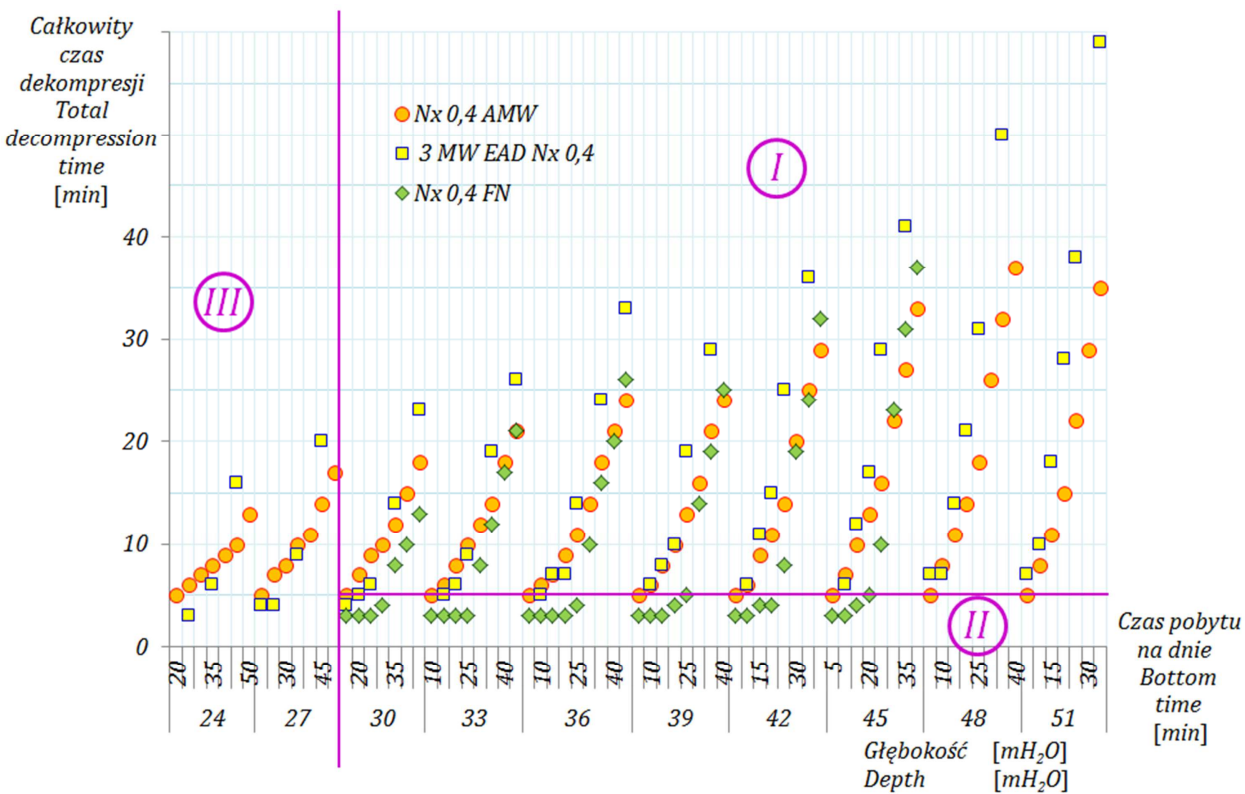

Fig. 4 Comparison of total decompression times for Nx - SCR CRABE SCUBA supplied with premix Nx 0.4 for selected decompression schedules according to French Navy FN, a procedured based on EAD conversion of decompression schedules from Table 3 MW and a newly developed procedure Nx 0,4 AMW

Such an approach is less effective in relation to short bottom times ${ }^{79}$ - fig. 4 area II. In the AMW approach, a different concept ${ }^{80}$ can be adopted for area II, allowing to shorten the decompression time for profiles with short stay times. This was not obtained by increasing decompression safety ${ }^{81}$. Short stay times are used in emergency situations, usually during ascent ${ }^{82}$. Omitting decompression stations recommended by the deep stops philosophy does not create an excessive increase in DCS risk, thereby in an emergency situation it is relatively safe to ignore them.

The decompression schedules for the area III marked in Fig. 4 should be clearly defined, as it is impossible to predict with certainty whether the ejector supporting ventilation of the breathing space during decompression will be switched on or off. Presumably this is the reason why the $F N$ did not publish data for this depth range.

For profiles with a maximum diving depth of more than $45 \mathrm{mH}_{2} \mathrm{O}$ the $\mathrm{FN}$ tables were not generated, probably owing to fear of an occurrence of CNSyn symptoms. Our own studies did not confirm a significant increase in the risk of CNSyn for this area, therefore these decompression schedules were allowed for use by the Polish Navy.

\section{Conclusions}

The article describes an example of a process approach to the development of a theory to plan underwater activities for the Nx-SCR AMPHORA SCUBA diving apparatus. As the basis of the planning process the basic scenario of the diving operation was defined. Based on the risk analysis of such an operation, emergency scenarios were generated. The baseline scenario and the emergency scenarios were used as the starting point for the determination of a minimal system that can ensure their implementation at the assumed reproducibility level with assumed precision at the required level of confidence or higher. Under some scenarios, the system was designed to ensure greater safety, hence it was expanded to include redundant elements.

The described approach was based on a developed national research theory for semi-closed respiratory systems in interaction with humans in hyperbaric conditions based on several models. The methodology of designing diving operations is based on an assumed level of risk ${ }^{83}$ taking into account the risk of an occurrence of the decompression sickness DCS and central oxygen toxicity CNSyn. Hence, further research ${ }^{84}$ may be conducted in a more targeted way with efficiency not yet available in Poland.

\section{REFERENCES}

1. Kłos R. 2011. The possibilities of decompression adjustment to CRABE rebreather - assumptions for standards and experimental dives. Gdynia : Polskie Towarzystwo Medycyny i Techniki Hiperbarycznej, 2011. ISBN 978-83-924989-4-0;

2. Kłos R. 2016. Trimix decompression system for CRABE rebreather. Gdynia : Polskie Towarzystwo Medycyny i Techniki Hiperbarycznej, 2016. ISBN 978-83-938322-5-5;

Stewart I. 1996. Does God play dice? - New mathematics of chaos. Warsaw : Wydawnictwo Naukowe PWN, 1996. ISBN 83-01-11371-5;

Birkes D., Dodge Y. 1993. Alternative methods of regression. brak miejsca : Jon Wiley \& Sons, Inc., 1993;

Mańczak K. 1976. Experiment planning technique. Warsaw : Wydawnictwo Naukowo-Techniczne, 1976. 519.2.001.5

Sporniak A. 2018. Church Evolution Theory. Tygodnik Powszechny. 23 September 2018, 2018, Vol. 3611, 39, pp. 32-35

Kłos R. 2007 a. The Use of Statistical Methods in Diving Technique - Script. Gdynia : Polskie Towarzystwo Medycyny i Techniki Hiperbarycznej, 2007. ISBN 978-83-924989-26;

8. Wald A 1947. Sequential Analysis. New York : Jon Willey \& Sons, Inc., 1947; 
9. Homer L.D. Weathersby P.K. 1985. Statistical aspects of the design and testing of decompression tables. Undersea Biomedical Research. 1985, Tom 12, 3, strony 239-249;

10. Kłos R. 2007. Mathematical modelling of the normobaric and hyperbaric facilities ventilation. Gdynia : Wydawnictwo Polskiego Towarzystwa Medycyny i Techniki Hiperbarycznej, 2007. ISBN 978-83-924989-0-2;

11. Kłos R. 2000. Dive equipment with regeneration of the respiratory mix. Poznań : COOPgraf, 2000. ISBN 83-909187-2-2;

12. Predictive studies IV. 1978. Work capability and physiological effects in He-O2 excursions to pressures of 400-800-1200-1600 fsw. Philadelphia: Institute for Environmental Medicine University of Pennsylvania, 1978. Report 78-1;

13. Report of proceedings Technical Symposium on The human factor in North Sea operational diving:. Proceedings Technical Symposium on The human factor in North Sea. 4-5 Nov1976. Heathrow : Hotel London, 4-5 Nov1976;

14. Frånberg O. 2015. Oxygen content in semi-closed rebreathing apparatuses for underwater use: Measurements and modeling. Stockholm : School of Technology and Health, 2015. ISSN 1653-3836;

15. Shykoff B. 2007. Performance of various models in predicting vital capacity changes caused by breathing high oxygen partial pressures. Panama City : Navy Experimental Diving Unit, 2007. NEDU Report TR 07-13;

16. Donald K.W. 1947. Oxygen poisoning in man part I. British Medical Journal. May 17, 1947, strony 667-672;

17. Donald K. 1992. Oxygen and the diver. Harley Swan: The SPA Ltd., 1992. ISBN 1-85421-176-5;

18. Harabin A.L. 1993. Human central nervous system oxygen toxicity data from 1945 to 1986. Bethesda : Naval Medical Research Institute, 1993. NMRI 93-03; AD-A268-225;

19. Kłos R. 2012. Possibilities of selection of oxygen-nitrox exposures for the AMPHORA rebreather-assumptions for standard and experimental dives. Gdynia : Polskie Towarzystwo Medycyny i Techniki Hiperbarycznej, 2012. ISBN 978-83-924989-8-8.;

20. NOAA. 2017. NOAA diving manual - diving for science and technology. [red.] Administration National Oceanic and Atmospheric. VI. Flagstaff : Best Publishing Co., 2017. ISBN 9781930536883;

21. Bühlmann A.A. 1984. Decompression-Decompression sickness. Berlin : Springer-Verlag, 1984. ISBN 3-540-13308-9; ISBN 0-387-13308-9;

22. Abysmal Diving Inc. 2001. Advanced Dive Planning Software. [CD] 6595 Odell Place, Suite G. Boulder Colorado, 80301 : Abysmal Diving Inc. 2001. ABYSS-2000 v.2.30.17;

23. Kłos R. 2013. Oxygen tolerance test. Polish Hyperbaric Research. 2013, Vol. 45, 4, pp. 69-78;

24. Tabele dekompresji i rekompresji nurków. 1982. Collective work. Gdynia : Dowództwo Marynarki Wojennej, 1982. Sygn.Mar.Woj. 860/81.

dr hab. inż. Ryszard Kłos, prof. nadzw.

AMW Akademia Marynarki Wojennej im. Bohaterów Westerplatte

Zakład Technologii Prac Podwodnych

81 - 103 Gdynia 3

ul. Śmidowicza 69

Tel: +586262746

ORCID identifier No: 0000-0002-4050-3978

${ }^{1}$ methodology is a set of rules concerning the ways of conducting selected processes

${ }^{2}$ Nitrox Semi-Closed Rebreather Self Contained Underwater Breathing Apparatus AMPHORA,

${ }^{3}$ theory is a general concept based on the identification and understanding of the relevant factors shaping a section of reality,

the method is an effective science-based procedure leading to the achievement of a defined objective; at a high level of detail the method becomes a science-based technique,

${ }^{5}$ for instance on: different scenarios of diving operations; effects of a stay under water; assessment of applied technologies; etc.,

${ }^{6}$ model describes an idealised system with the occurring idealised process being a copy or model of a real system in which real processes occur,

${ }^{7}$ based on causative result of each experiment implementation, as opposed to a random occurrence which may take place or not under a defined set of experimental conditions,

${ }^{8}$ the word stochastic is of Greek origin and means "skillful in pursuing a goal", expressing the idea of using the laws of randomness for personal gain [3],

${ }^{9}$ it does not reflect the entire field of variability of process parameters and therefore can only be treated as an interpolation approximation used to predict the later state or behaviour of the process,

${ }^{10}$ related to the concept of probability and, contrary to the commonly understood randomness, to which the rules of probability cannot always be applied,

${ }^{11}$ statistical description of responses to forced actions is a frequent way of estimating the behaviour of complex phenomena,

12 random phenomena are divided into three types: random events, random variables and stochastic processes. The probability calculus examines the regularity of events, variables and random processes. Mathematical statistics deals with methods of inference about the distribution of random variables on the basis of observations, thus constituting a separate mathematical discipline having its own subject of research [5],

${ }^{13}$ descriptive statistics that serves to better illustrate data by extracting from them information for a better understanding of the meaning of the data obtained rather than for inquiring into their nature,

${ }_{14}$ common knowledge, universal, based on common sense, artistic and literary knowledge, speculative,

${ }^{15}$ factual knowledge subject to agreed content and methodological requirements,

${ }^{16}$ over system,

17 language should be treated here as a resource of elements and ways of using them for communication,

${ }^{18}$ science about science, which studies sciences from the point of view of their structure and the methods of their justification,

${ }^{19}$ from a pragmatic point of view, it is the science of methods of scientific activity and research procedures applied in science,

${ }^{20}$ validation is confirmation of the reproducibility of the assessed process occurring in a defined system with the required precision at the assumed or higher confidence level,

${ }^{21}$ the definition was certainly consulted with the Pontifical Academy of Sciences, which includes the scientific societies of eminent representatives of mathematical and natural sciences from various countries appointed by the Popes,

${ }^{22}$ the common necessity to use stochastic modelling is, however, connected with frequently encountered overinterpretation, leading to too far-reaching generalisations that are not supported by the methods used,

${ }_{23}^{23}$ similar to the testing of new medicines or clinical procedures

${ }_{25}^{24}$ diving apparatus - diver

25 most often one variable parameter is adopted for this multiplication, i.e. the experimental diver, thus extending the inference to include a selected population of divers,

${ }^{26}$ an occurrence or non-occurrence of DCS symptoms,

${ }^{27}$ which explains the long time needed to confirm the authorisation of pharmaceuticals for sale,

${ }_{28}^{27}$ which explains the long time needed

${ }^{29}$ under domestic conditions it is theoretically possible to carry out max. 150 experimental dives per year, but the cost of such an approach is approximately

PLN 1 million net,

${ }^{30}$ for instance, by defining system limitations,

${ }^{31}$ if redundant elements are required owing to the way the system is built, for example for safety reasons, such an approach is also reflected in the term 'reasonably minimal set of elements' used here,

32 joint action is stronger than the sum of separate actions,

${ }^{33}$ that lies outside the system but has an impact on its functioning,

34 taking into account not only financial viability but also social impacts,

${ }^{35}$ system engineering is used in technique, the same basis is assigned to system analysis used in management sciences,

${ }^{36}$ about 35 years ago

${ }^{37}$ and the use of statistical models was reserved only for the validation process

usually concerning the volume of ventilated space, 
${ }^{39}$ there are at least several recommended approaches: neo-haldanian, RGBM, VPM etc.,

${ }^{40}$ the ratio of consumed oxygen stream $\dot{v}$ to ventilation stream $\dot{V}_{\mathrm{E}}: \varepsilon=\frac{\dot{v}}{\dot{\mathrm{V}}_{\mathrm{E}}}$,

${ }^{41}$ accuracy

42 for example, similarly to the role of ventilated volume in a submarine ventilation model,

${ }^{43}$ the group's representativeness is limited to divers meeting the criteria for military divers,

${ }^{44}$ in relation to oxygen content in the premix $x_{\mathrm{W}}$ supplied in the breathing space

${ }^{45}$ for stabilised values of divers' respiratory parameters,

${ }_{48}^{46}$ in the case of anaerobic organisms, it is a deadly toxic agent,

${ }^{48}$ symptoms similar to lung burning with chemicals,

49
in relation to the central nervous system,
reduced red blood cell count, reduced vital lung capacity, oxygen-induced blindness, etc.,

${ }^{50}$ this theory is the basis for epidemiological research, research on population size and biodiversity, machine reliability, risk analysis, etc.

${ }^{51}$ the return to the state prior to oxygen exposure, consisting in deactivation of potentially dangerous reactive oxygen species by biochemical mechanisms

as a result of exposure to high partial pressures of oxygen,

52 commonly used in computer programmes for planning civil technical dives [22]

considered dangerous to a vast number of divers

${ }^{54}$ possibility of decompression at the last station at the depth of $6 \mathrm{mH}_{2} \mathrm{O}$, possibility of discontinuation of oxygen decompression, possibility of additional effort load, taking into account previous dives, taking into account the type of transport, taking into account low temperature dives, etc,

${ }^{55}$ these deviations occur when a diver has a considerably developed muscle tissue compared to a regular muscle tissue, for this reason one diver was rejected,

${ }^{56}$ reproducibility and repeatability,

${ }^{57}$ for example, in the preparation of a diver's physical condition, reduction of the effectiveness of the breathing space ventilation, inappropriate preparation of breathing mixes or decrease of their required quality, inappropriate packing of the absorber or decrease of its quality parameters, etc.

58 describing cases of diseases with a rare course or a rare incidence

${ }^{59}$ such as a positive result of an oxygen tolerance test,

${ }^{60}$ usually for recreational dives the risk is indicated at the level of $p=1 \%$ and for combat dives $p \leq 5 \%$ with the significance of $\alpha=0,01$,

${ }^{61}$ outside the saturation zone, it is hazardous to expose the diver to a greater amount of effort,

${ }^{62}$ rest will be necessary for the performance of mine work or due to tactical situation related to the need to reduce noise emissions, but in such a case the problem of an increased risk of oxygen poisoning needs to be considered

63 for instance, with an open circulation of the breathing mix,

64 for instance, in the form of additional apparatuses carried by the diver or suspended in midwater,

65 it is possible to add numerous other system elements, such as a communication subsystem increasing mental comfort, which has a significant impact on decompression processes

speeding up,

${ }^{67}$ for instance, in the case of oxygen supply failure,

${ }^{68}$ suspended in midwater or additional breathing apparatuses carried by the diver,

${ }^{69}$ according to Canadian practice, in Poland it was permissible to introduce an interruption of up to 5 minutes,

${ }^{70}$ in such a case there is a much greater certainty that the diver will reach the decompression chamber in time,

${ }_{72}^{71}$ prediction,

72 a natural example can be such an understanding of weather processes taking place in the atmospheric system that allows to predict weather phenomena with sufficient repeatability and satisfactory precision,

${ }_{74}^{73}$ sufficiently precise and reproducible for the intended applications,

74 based on scientific predictions of the pathways of future processes or changes in system characteristics,

${ }^{75}$ Equivalent Air Depth,

${ }^{76}$ marginalisation consists in not taking into account the initial higher oxygen concentration in the circulating breathing mix inhaled by the diver,

${ }^{77}$ shorter,

${ }_{78}$ the depth of $24 \mathrm{mH}_{2} \mathrm{O}$ is only added as an approximate theoretical value, because in this case the ejector operation may not be ensured,

${ }^{79}$ obserwowane na rys. 4 skrócenie czasów dekompresji w stosunku do poprzednio stosowanej technologii opartej o przeliczenia EAD nie powoduje

${ }^{79}$ the reduction in decompression times observed in Fig. 4 compared to the previous technique based on EAD calculations does not cause a significant increase in DCS risk, as the approach adopted was based on the philosophy of deep stops,

${ }^{80}$ such a project can be based on calculations for higher oxygen contents at the beginning of a dive,

81 for example, in the case of an inefficiently performed ventilation procedure of the breathing space with premix,

82 sometimes for fast intervention dives

${ }^{83}$ acceptable appetite for risk,

${ }^{84}$ for example, on different scenarios of diving operations, underwater effort burden, combining diving operations with combat effort burden, air transport, application of reproducible or repetitive diving procedures, etc. 